\title{
REDUCE AND OFFSET YOUR CARBON FOOTPRINT AND LIVE A CARBON
}

\author{
NEUTRAL LIFE \\ SIVAPRIYA BALAGOPAL ${ }^{1} \&$ MARY CELINE JOE NIDHIRY ${ }^{* 2}$ \\ ${ }^{1}$ Head of Department, Department of New Product Development and Research\& Development, M. E. Meeran Innovation Center, \\ Eastern Condiments Pvt. Ltd, Cochin, India \\ 2*Senior Officer, Department of New Product Development and Research\& Development, M. E. Meeran Innovation Center,
}

Eastern Condiments Pvt. Ltd, Cochin, India

\begin{abstract}
Carbon footprint is a primary concern for the environment today. It is the amount of greenhouse gas emissions that are released into the atmosphere and affect our nature, that are a result of our day to day activities. We might not realize that our lifestyle is in fact a very large contributor to the carbon footprint. Being aware about the damage we cause to our environment is important or else we will continue to do the same leaving behind an uninhabitable space for the future. Our willingness to adopt small changes in our lifestyle along with carbon offsetting for those inevitable activities can help to walk into a fresher air and lead a carbon neutral life. By making small changes to our actions, we can start making a big difference.
\end{abstract}

KEYWORDS: Carbon Footprint, Carbon Offset, Carbon Neutral Life, Greenhouse Gases.

Received: Feb 11, 2021; Accepted: Mar 31, 2021; Published: Apr 10, 2021; Paper Id.: IJASRJUN20211

\section{INTRODUCTION}

A Carbon footprint amounts to the whole of emitted greenhouse gases through the production, use and end-of-life of a product or a service. It could be either direct or indirect emissions. These emitted gases could be carbon dioxide, methane, nitrous oxide or fluorinated gases. A large carbon footprint has detrimental effects on the environment. They elevate the Earth's temperature and causes global warming by trapping heat in the atmosphere. We might have never thought about our contribution to carbon footprint or even realized that our day to day activities are a major contributor. An awareness of how our actions impact the environment, adopting ways of reducing them and offsetting them will thereby help to reduce the negative effects of carbon footprint and lead us on the road towards a better tomorrow. We, as an individual or an organisation or government or business, can all think creatively to be a part of the solution.

\section{What can be done to Reduce our Footprint?}

Each and every individual adds to the percentage of carbon footprint. We might wonder how? Our lifestyle plays a major role in this contribution; our mode of transportation, the food we eat, the things we buy, the lights and appliances at home and what we wear; all these count. With awareness and our willingness to embrace few changes in the way we live can help reduce our footprint to a great extent.

The connection between meat and climate change is unknown to many. Red meat consumes a large amount of water and also produces more emissions than poultry. Globally, livestocks are responsible for an annual emission of methane equivalent of 3.1 gigatonnes of carbon dioxide into the atmosphere. 


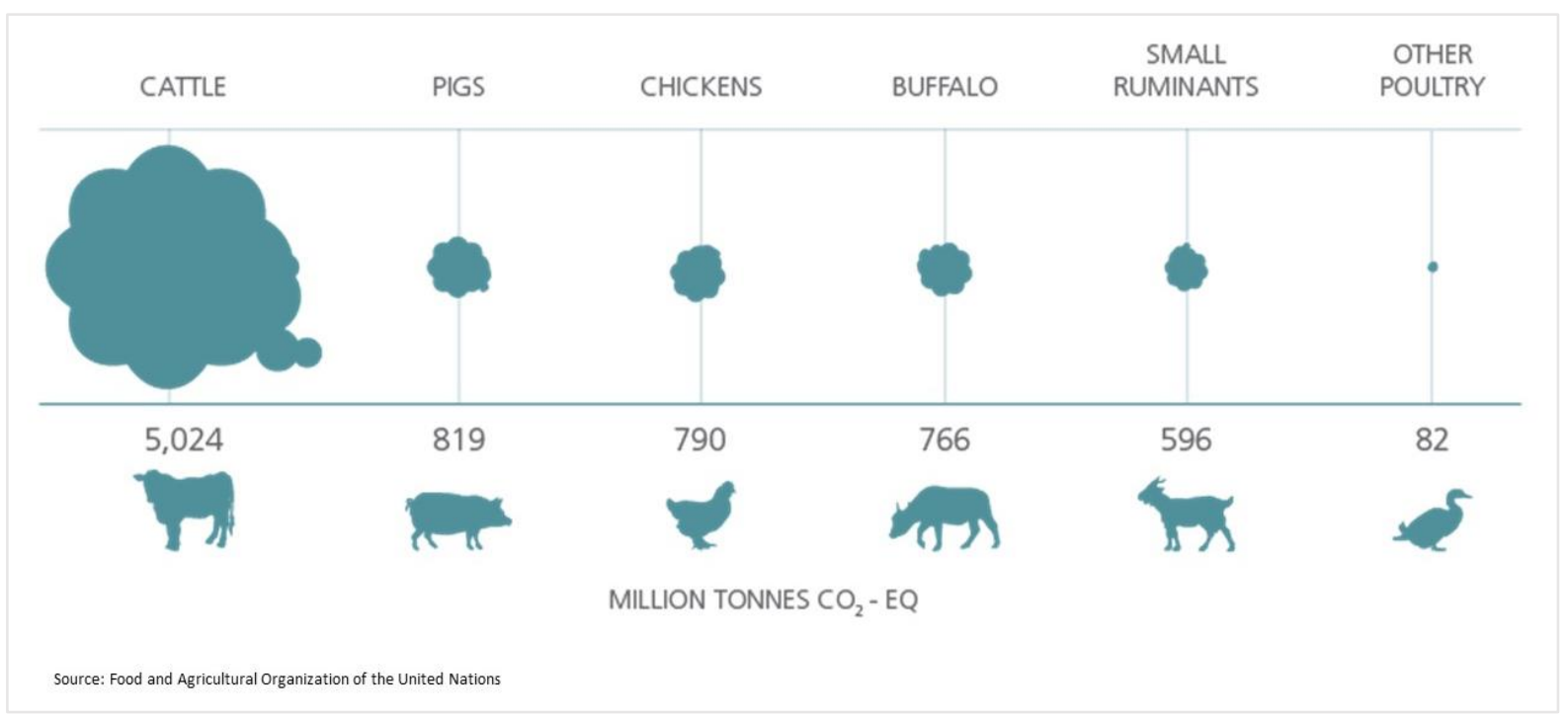

Figure 1: Emissions by Species. This Global Estimate Includes Emissions with Regard to Both Edible Products and Other non Edible Outputs or other Goods and Services (Wool and Draught Power). Main Contributor to the Sector is Cattle and beef (about 5.0 gigatonnes $\mathrm{CO}_{2} \mathrm{eq}$ ) around 62 percent. Pigs, Buffalo, Ruminants and poultry Contribute Very Less to the Sector's Emissions Around 7 to 11 Percent.

Following a vegan diet or eating less meat can help to solve our problem and bring a drastic change to our climatic problems.

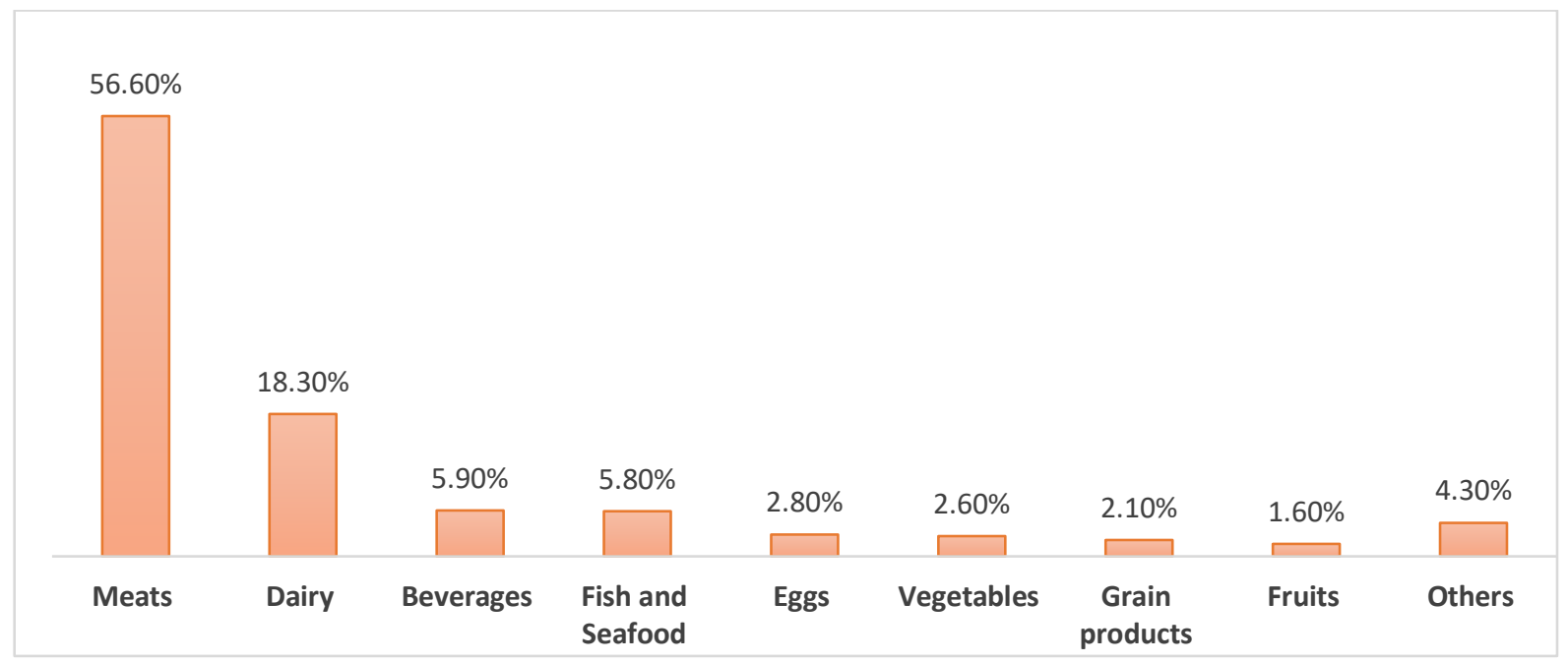

Figure 2: Contribution of Greenhouse Gas by Various Foods in an Average Diet. Food Products Including Production and Transportation Contribute to Carbon Footprints. Production Account for More Carbon Emissions than Transportation. Meat and Meat Products are the Largest Contributors than Vegetables, Fruits and Grain Products.

Reduced wastage of food and buying according to our needs can also bring about the change. Waste from all food products don't contribute equally to the emissions. Carbon emissions of meat and dairy products are much higher compared to fruits and vegetables. For example, in 2018, a study in the UK found that $25 \%$ of edible household food waste from fresh fruits and vegetables account to $12 \%$ of GHG emissions, but $8 \%$ fish and meat waste account for $19 \%$ of GHG emissions. Cutting down on the amount of non-vegetarian food waste can be of better help in reducing the footprint than vegetarian food waste. Proper planning to collect food waste and also proper waste disposal such as anaerobic digestion, home composting, and incineration are better than landfill. Some countries like Denmark have already banned the sending of organic waste to landfill. According to estimation by a research organization, by identifying potential solutions to 
climate change by 2050, it is possible to reduce emissions by 2.1 billion tonnes if worldwide composting levels increased. Eating in the house, organic produce and also seasonal and local produce can reduce the carbon footprint of transportation and use of plastic packaging. Planting trees, bee friendly flowers or a vegetarian garden can mitigate the urban heat island that occurs due to the replacement of natural land cover with dense concentrations of buildings, pavements and other surfaces that absorb and retain heat.

Similarly, our total attire contributes to a large amount of carbon footprints. A polyester shirt generates about 5.5 $\mathrm{kg}$ carbon dioxide equivalent while a cotton shirt produces $2.1 \mathrm{~kg}$ carbon dioxide equivalent. Slowing down on fast fashion cycle can help to reduce the overconsumption challenge. Some sound ways are to use second-hand clothing that is giving a second life to the clothes, buying less, sending old torn clothes for recycling and passing on old wearable clothes to family, relatives, friends or charity. UK recycling charity WRAP has set up a website "Love Your Clothes" that gives various tips to repair and extend the life of clothes can help reduce the footprint of clothes. It is estimated that in the UK, the environmental impacts could be reduced by $20-30 \%$ by just actively continuing to wear a garment for 9 months longer. BioCouture or fashion with environmentally sustainable materials is preferred by various brands in the fashion industry and also by the consumers. New innovations in clothing such as using up waste from fruits, wood and other natural materials or other easily biodegradable materials to produce textiles and also alternate ways of fabric dyeing are of great use to reduce the footprint. Not washing clothes always, instead hang them out to air and heat, hence reducing the use of water and the amounts of microfibers shed. Reducing our wardrobe carbon footprint can help to improve our environmental conditions.

Poorly insulated housing, use of old gas and oil boilers, lighting in our houses or workplaces, the home appliances we use, the goods and services all accounts to footprint. Insulating roof, walls and windows could reduce kilograms of carbon being emitted into the outer space as well give the best suitable degree in the living space. Upgrading to new boilers and other appliances could save energy and reduce heat emissions. Another most effective way to save energy in the long run is to install solar panels. If we are planning to reduce our carbon footprints at home all of a sudden then watch out for some small things like switching to LED, turning off the switches when not in use, unplugging the devices and using water saving shower heads. As plastics are damaging our environment, it is always better to buy biodegradable goods. Always consider to recycle and reuse all possible items. Using our appliances like baking oven during the time when carbon intensity is lowest is also a measure to reduce footprint. A Carbon Intensity App was launched by National Grid ESO that helps to reduce our carbon footprint and also electricity bills by showing the greenest time to use electricity in a day and also offers real-time data on how energy is currently being produced.

Similarly, taking care of our commute can also create a big difference to the environment. The distance we drive, maintaining our car, how frequent we use our car all these matters. A large car emits more greenhouse gases than smaller vehicles. Ride hailing (customised ride hired via online application) has become the new normal. Based on a report by the Union of Concerned Scientists in the US, ride hailing services are the highest contributor to climate pollution. On an average $69 \%$ and $47 \%$ more climate pollution is caused by ride hailing compared to the journeys they displace and an equivalent private car ride respectively, due to deadheading (extra passenger free ride they drive while waiting for a fare). Preferring cycle, bike, trains or other public transport over private cars to travel for work are all alternatives. Walking over the distances possible is a no emission option. Avoiding aviation whenever possible is a very good way to reduce large amounts of carbon footprint. Trains and coaches are the lowest carbon emitters. Compared to flying, driving is less carbon 
intensive. Under unavoidable flight travels, we can still cut down on the emissions by carrying fewer luggages, booking an economy ticket, choosing to fly with the airlines that produce less carbon dioxide emissions and also by choosing direct flights without layovers.

In this technology oriented world our dependence on electronics and gadgets is a major contributor to carbon footprints. Apple said $74 \%$ of their overall carbon emissions are produced during product manufacturing. So manufacturing a gadget generates a huge amount of these emissions. The way we send messages, make calls, and various posts in social media and various newsletter subscriptions are all contributing to our digital carbon footprint. Our digital footprint can be reduced by altering the way we buy and use our gadgets. Based on a study at the University of Edinburgh, extending the usage period of a single monitor or a computer from four to six years can prevent carbon emissions equivalent to 190kg. According to Mike Berners - Lee, carbon footprints researcher at Lancaster University, $135 \mathrm{~kg}$ (298 lbs) $\mathrm{CO} 2$ eq is generated from sending emails by a typical business user. Based on the estimates by antispam service Cleanfox, around 2850 unwanted emails responsible for $28.5 \mathrm{~kg} \mathrm{CO} 2$ eq are received every year by an average user from subscriptions. Stopping "thank you" emails, unsubscribing from newsletters or other mail sources that we no longer read, avoiding multiple recipient messages and swapping emails with link attachments could reduce tonnes of emissions. Switching to read books and news online is more sustainable than poring over paper. Another tricky area to keep our carbon footprint down is to reduce the usage of YouTube or other social sites to tackle our boredom. Some other good ways are to switch off automatic downloads, turning off unnecessary cloud backups, changing the auto play settings and switching to lower resolution from high resolution videos when not necessary. Buying physical CD is better if we are repeatedly listening to the same album, but streaming is better if in case we listen to music less than 27 times over our lifetime. Unnecessary phone calls, or long duration calls could be avoided as it gives off more carbon than text messages.

Industries are a large contributor of greenhouse gases, hence leaving behind a bigger carbon footprint. Various sectors emit different levels of greenhouse gases as illustrated. In the year 2016, global greenhouse gas emissions were 49.4 billion tonnes $\mathrm{CO}_{2}$ eq. Climate watch and World Resource Institute had studied the latest breakdown of global emissions by various sectors and depicted in Figure 3. It could be clearly understood that the highest emission is from energy use accounting for almost three quarter and the lowest emission is from industry and waste accounting to $8 \%$. Agriculture and land use make up almost one-fifth of the emissions \& in considering the food system as a whole (processing, packaging, transporting \& retail) it increases to one quarter. 


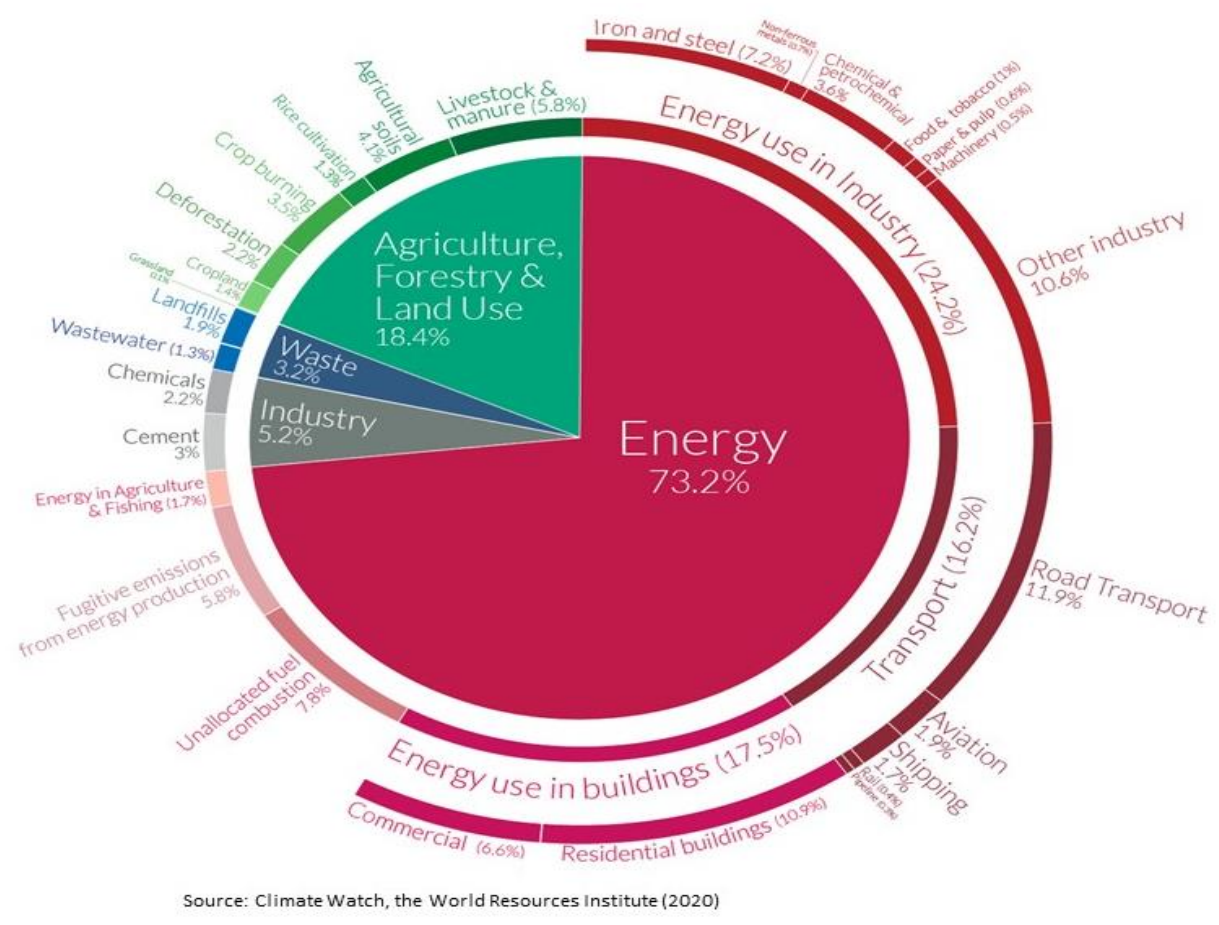

Figure 3: Global Green House Gas Emissions by Sector.

So, by making such small changes in our thoughts, we can reduce our footprint to breathe fresh. It might not be possible for us to cut down on all that we do to attain zero carbon footprints. An alternative solution to attain carbon neutral for those emissions caused by inevitable activities is Carbon Offset.

\section{What is Carbon Offset?}

Carbon Offset is the reduction in emission of carbon dioxide and other greenhouse gases made in order to compensate for the emissions made elsewhere. It is measured in tonnes of carbon dioxide equivalent. It could be bought, sold or traded as part of a carbon market. Our day-to-day actions such as driving, use of electronics, flying consume energy and emit carbon. Though we try to reduce these emissions, there could be some unavoidable situations where we are forced to contribute these emissions. In such circumstances we can balance the emissions made by buying a carbon offset project. A wide range of carbon offset projects is available that could not only help reduce carbon but also provide wider benefits such as biodiversity, food security, jobs, education, health and well-being in developing countries. There are various companies and individuals investing in offset projects to achieve their goal of carbon negative. To reduce the carbon footprint of the operations, Google uses a combination of renewable energy and carbon offset. It was told by Google CEO Sundar Pichai that Google has eliminated their entire carbon legacy covering all the operational emissions before becoming carbon neutral in 2007 through the purchase of high quality carbon offsets. Now, their lifetime net carbon footprint is zero. They are the first major company to get this done. Similarly, we can also buy various offset projects in order to balance the emissions made through our activities. 




Figure 4: How Carbon Offset Works?

\section{How to Live a Carbon Neutral Life?}

What is meant by Carbon Neutral? Being carbon neutral involves calculating your total climate-damaging carbon emissions, reducing them where possible, and then balancing your remaining emissions, often by purchasing a carbon offset: paying to plant new trees or investing in "green" technologies such as solar and wind power, according to the New Oxford American dictionary which made this term "Word of the Year," in 2006. Companies like Microsoft, Sky, Logitech and many others have achieved their goal of carbon neutral through the purchase of various Carbon Offset projects.

- Sky has invested in more than 30 emissions reductions projects that include renewable energy projects in India, forest conservation in Indonesia and rainforest conservation in Brazil. They work with their customers and suppliers to reduce their emissions in both upstream and downstream processes. At present, $78 \%$ of their top 50 suppliers have included climate change initiatives into their strategies. Sky also produced the world's first automatic standby mode for its set-top boxes in order to support the reduction of emissions by customers. Through the combination of efficiency measures, renewable energy generation and procurement, product innovation and external emission reduction projects Sky is a CarbonNeutral ${ }^{\circledR}$ company.

- Microsoft made various reductions in their product emissions through reduction in its energy use since the launch of Xbox. Across their manufacturing units they use 100\% renewable energy. Finally, by financing the Sichuan China Bio digesters project Microsoft made the Xbox consoles carbon neutral.

- Logitech reduces their carbon impact with the innovation of the most energy efficient wireless gaming sensor HERO (High Efficiency Rated Optical), packaging efficiencies such as reducing overall weight, eliminating PVC, and replacing plastics with alternate materials. Finally, with the purchase of emissions reductions projects around the world, Logitech achieved carbon neutrality. Logitech in partnership with Natural Capital Partners financed forestry protection projects in Brazil, Canada and Indonesia and renewable energy and solar cooker projects in China. 
Through small changes in our lifestyle and purchase of carbon offset projects, we can also attain a carbon neutral life. There are many websites offering various offset projects. They also help to calculate our emissions from various activities and to invest in various projects based on our calculated emissions and also receive a certificate for the offsetting.

\section{CONCLUSIONS}

Carbon Footprint is a great concern that affects the environment today. Many individuals and companies are targeting for a carbon neutral life in an effort to protect the environment for the future generations to come. An awareness of the contributions to a footprint arising from our day to day activities and embracing few changes in our lifestyle can reduce our footprint to a very large extent. While it may be difficult to adopt every change and achieve carbon neutral life totally, we may target the remaining emissions by even investing in projects or ways to offset the equivalent footprint.

\section{REFERENCES}

1. (n.d.). Retrieved from https://www.carbonfootprint.com/

K. Bhaskar, L. R. Sassykova, M. Prabhahar \& S. Sendilvelan, "Effect of Dimethoxy-Methane (C3H8O2 ) Additive on Emission Characteristics of a Diesel Engine Fueled with Biodiesel", International Journal of Mechanical and Production Engineering Research and Development (IJMPERD), Vol. 8, Issue 1, pp, 399-406

2. (n.d.). Retrieved from https://www.carbonfootprint.com/carbonneutrality.html

C. Uma Maheswari, R. Meenakshi Reddy \& Burigala Vinodh, " Design and CFD Analysis of Food Dryer Using Solar Flat Plate Collector and Exhaust Gas with Finned Copper Tubes ", International Journal of Mechanical and Production Engineering Research and Development (IJMPERD), Vol. 8, Issue 6, pp, 335-348

3. (n.d.). Retrieved from First Climate: http://www.firstclimate.com/en/carbon-offsetting-with-first-climate/ Rekam Manikumar, Rajasekhar S. \& Santosh Kumar, "Performance and Emission Characteristics of a CI Engine Fueled With Biodiesel Extracted From WCO-Mustard Oil ", International Journal of Mechanical Engineering (IJME), Vol. 7, Issue 3, pp; $21-30$

4. (n.d.). Retrieved from Certified Carbon Neutral Global Standard: https://www.carbonneutral.com/

Dipu Kumar \& Mohammad UL Hassan, "Experimentation and Performance Evaluation of Heat Recovery from Domestic Refrigerator",International Journal of Mechanical Engineering (IJME) ISSN (P): 2319-2240; ISSN (E): 2319-2259 Vol. 7 , Issue 3, pp; 41 - 50

5. (n.d.). Retrieved from https://www.carbonneutral.com/examples/microsoft

Dr. Apoorva Trivedi, "Green HRM: Traditions and Designed Effort in the Organizations ",BEST: International Journal of Management, Information Technology and Engineering (BEST: IJMITE), Vol. 3, Issue 12, pp, 29-36

6. (n.d.). Retrieved from https://www.carbonneutral.com/examples/sky

Monika Sharma, "Green Supply Chain- A Tool to Eradicate the Problems of Global Environment", BEST: Journal of Management, Information Technology and Engineering (BEST: JMITE) Vol. 1, Issue 1, pp, 53-58

7. (n.d.). Retrieved from https://www.carbonneutral.com/examples/logitech

8. 6 companies helping to create the zero-carbon economy of the future. (2019, September 19). Retrieved from We mean Business: https://www.wemeanbusinesscoalition.org/blog/6-companies-helping-to-create-the-zero-carbon-economy-of-thefuture-2/ 
9. Albeck-Ripka, L. (n.d.). How to Reduce Your Carbon Footprint. Retrieved from The New York Times: https://www.nytimes.com/guides/year-of-living-better/how-to-reduce-your-carbon-footprint

10. Carbon Neutrality. (n.d.). Retrieved from https://www.carbonfootprint.com/carbonneutrality.html

11. Clark, D. ( 2011, September 16 ). A complete guide to carbon offsetting. Retrieved from The Guardian : https://www.theguardian.com/environment/2011/sep/16/carbon-offset-projects-carbon-emissions

12. Cole, L. (2020, November 17). How to cut carbon out of your heating. Retrieved from BBC Future: https://www.bbc.com/future/article/20201116-climate-change-how-to-cut-the-carbon-emissions-from-heating

13. Could you live a low carbon life? Meet the people who already are. (n.d.). Retrieved from The Guardian: https://www.theguardian.com/uk-news/2019/may/04/carbon-cutting-zero-emissions-eco-warriors-damaged-world

14. Fleischmann, M. (2019, September 23). How Much Do Our Wardrobes Cost to the Environment? Retrieved from The World Bank : https://www.worldbank.org/en/news/feature/2019/09/23/costo-moda-medio-ambiente

15. GLEAM 2.0 - Assessment of greenhouse gas emissions and mitigation potential. (n.d.). Retrieved from Food and Agriultural Organization of the United Nations : http://www.fao.org/gleam/results/en/

16. Goodall, C. (2017, January 19). How to reduce your carbon footprint. Retrieved from The Guardian: https://www.theguardian.com/environment/2017/jan/19/how-to-reduce-carbon-footprint

17. Griffiths, S. (2020, March 6). Why your internet habits are not as clean as you think. Retrieved from BBC Future : https://www.bbc.com/future/article/20200305-why-your-internet-habits-are-not-as-clean-as-you-think

18. Harrabin, R. (2019, August 8). Plant-based diet can fight climate change - UN. Retrieved from BBC News: https://www.bbc.com/news/science-environment-49238749

19. Harrabin, R. (2020, May 20 ). Climate change: Top 10 tips to reduce carbon footprint revealed. Retrieved from BBC News : https://www.bbc.com/news/science-environment-52719662

20. Harrabin, R. (2020, January 23). Cut meat and dairy intake 'by a fifth', report urges. Retrieved from BBC News: https://www.bbc.com/news/science-environment-51210622

21. Holbrook, E. (2020, September 14). Google Becomes First Major Company to Claim a Carbon Footprint of Zero. Retrieved from Environment+Energy Leader: https://www.environmentalleader.com/2020/09/google-becomes-first-major-company-toclaim-a-carbon-footprint-of-zerol

22. How to reduce your carbon footprint: Simple and easy steps to fight climate change. (n.d.). Retrieved from OVO Enegy: https://www.ovoenergy.com/blog/green/ways-to-reduce-your-carbon-footprint.html

23. https://www.ecotricity.co.uk/our-news/2018/the-carbon-footprint-of-getting-dressed. (2018). Retrieved from Ecotricity: https://www.ecotricity.co.uk/our-news/2018/the-carbon-footprint-of-getting-dressed

24. Leahy, S. (2019, June 10). Choosing chicken over beef cuts our carbon footprints a surprising amount. Retrieved from National Geographic: https://www.nationalgeographic.com/environment/article/choosing-chicken-over-beef-cuts-carbonfootprint-surprising-amount

25. Nassos Stylianou, C. G. (2019, August 9). Climate change food calculator: What's your diet's carbon footprint? Retrieved from BBC News: https://www.bbc.com/news/science-environment-46459714

26. Neus González, M. M. (2020 , May 29). Meat consumption: Which are the current global risks? A review of recent (20102020) evidences. Retrieved from NCBI: https://www.ncbi.nlm.nih.gov/pmc/articles/PMC7256495/ 
27. Now Offset Carbon. (n.d.). Retrieved from https://www.itmustbenow.com/tools/sustainability/carbonoffset/

28. Oakes, K. (2020, February 26). How cutting your food waste can help the climate. Retrieved from BBC Future: https://www.bbc.com/future/article/20200224-how-cutting-your-food-waste-can-help-the-climate

29. Pichai, S. (2020, September 14). Our third decade of climate action: Realizing a carbon-free future. Retrieved from Google Official blog: https://blog.google/outreach-initiatives/sustainability/our-third-decade-climate-action-realizing-carbon-freefuturel?_ga=2.87456977.893218712.1600117920-1696827086.1600117920

30. Ravilious, K. (2020, April 02 ). Life in a carbon-neutral world. Retrieved from Physics World: https://physicsworld.com/a/lifein-a-carbon-neutral-world/

31. Ritchie, H. (2020, February 04). Less meat is nearly always better than sustainable meat, to reduce your carbon footprint. Retrieved from Our World in Data: https://ourworldindata.org/less-meat-or-sustainable-meat

32. Ro, C. (2020, March 11). Can fashion ever be sustainable? Retrieved from BBC Future: https://www.bbc.com/future/article/20200310-sustainable-fashion-how-to-buy-clothes-good-for-the-climate

33. Roser, H. R. (n.d.). Emissions by sector. Retrieved from Our World in Data: https://ourworldindata.org/emissions-by-sector

34. Selin, N. E. (n.d.). Carbon offset. Retrieved from Britannica: https://www.britannica.com/technology/carbon-offset

35. The carbon footprint of getting dressed. (2018). Retrieved from Ecotricity Our News: https://www.ecotricity.co.uk/ournews/2018/the-carbon-footprint-of-getting-dressed

36. Timperley, J. (2020, March 18). How our daily travel harms the planet. Retrieved from BBC Future : https://www.bbc.com/future/article/20200317-climate-change-cut-carbon-emissions-from-your-commute

37. Vera Hoffman, S. W. (2009, May 12). Can People Really Have Carbon-Neutral Lives? Retrieved from Scientific American : https://www.scientificamerican.com/article/can-we-be-carbon-neutral/

38. Watts, B. G. (2019, August 7th ). The cows that could help fight climate change. Retrieved from BBC Future: https://www.bbc.com/future/article/20190806-how-vaccines-could-fix-our-problem-with-cow-emissions 
